\title{
Modulation of Neutrophil Function by Lysozyme
}

\author{
POTENTIAL NEGATIVE FEEDBACK SYSTEM OF INFLAMMATION
}

\author{
Leo I. Gordon, Steven D. Douglas, Neil E. Kay, Osamu Yamada, Elliott F. \\ OsSERMan, and HARRY S. JACOB, Department of Medicine, University of \\ Minnesota Medical School, Minneapolis, Minnesota 55455; Cancer Research \\ Center of the Institute of Cancer Research, Columbia University, College of \\ Physicians and Surgeons, New York 10032
}

\begin{abstract}
A B S T R A C T Host responses to infectious organisms should be modulated so that tissue-damaging products of inflammatory cells do not produce excessive destruction of normal tissue. Lysozyme, which is continuously secreted by monocytes, which, in turn, migrate relatively late to inflammatory areas, was found to significantly dampen several responses of neutrophils to inflammatory stimulants. Thus, human lysozyme obtained and purified from the urine of patients with monocytic leukemia (but not its structurally similar and comparably cationic analogue, eggwhite lysozyme) depresses chemotaxis of normal neutrophils to activated complement, bacterial supernate, and $N$-formylmethionylphenylalanine. In addition, human (but not eggwhite) lysozyme depresses oxidative metabolism (hexose monophosphate shunt activity) and superoxide generation of neutrophils. The specificity of the suppressive effects was indicated by inhibition studies with rabbit antihuman lysozyme antibody, and with the trisaccharide of $\mathrm{N}$-acetylglucosamine, a specific inhibitor of lysozyme. The results suggest that lysozyme, a product of inflammatory cells themselves, may function in a negative feedback system to modulate the inflammatory response.
\end{abstract}

\section{INTRODUCTION}

Although secreted by monocytes (1), and present in large amounts in lysosomes of polymorphonuclear leukocyte(s) $(\mathrm{PMN})^{1}(2)$, the function of lysozyme in inflammatory and immune responses is largely unknown. Since its discovery as a bacteriolytic factor in 1922 (3), a role for lysozyme in host defenses has been

\footnotetext{
Address reprint requests to Dr. Jacob, University of Minnesota Hospitals, Minneapolis, Minn.

Received for publication 30 October 1978 and in revised form 8 March 1979.

${ }^{1}$ Abbreviations used in this paper: PMN, polymorphonuclear leukocyte(s); tri-NAG, trisaccharide of $\mathrm{N}$-acetylglucosamine.
}

suggested by some $(3,4)$, but questioned by others (5-7), mainly because most pathogenic bacteria are insensitive to its lytic activity $(3,8-10)$ in the absence of other enzymes, antibody and complement. Recently, lysozyme has been shown to alter the shape and adherence of mammalian cells in culture (11), raising the possibility that it may somehow serve as a regulator of membrane phenomena. Thus far, the identity of its target substrate in mammalian cells remains unknown.

The fact that lysozyme is secreted by phagocytes suggested that investigation of its effects on inflammatory cells themselves might be profitable. Monocytes continuously secrete lysozyme (1) and migrate relatively late to areas of inflammation - well after PMN. From this pattern, we hypothesized that lysozyme might modulate PMN membrane function so as to diminish excessive tissue injury attendant to PMN phagocytic activity. Indeed, the results of the present studies which have been published in preliminary form elsewhere (12) demonstrate that human lysozyme, but not its closely similar analogue obtained from hen eggwhite, is a potent inhibitor of chemotaxis and of the production of toxic oxygen radicals by stimulated PMN.

\section{METHODS}

Neutrophil isolation. Neutrophils obtained from normal laboratory personnel were purified in different ways for different studies. For chemotaxis assays, heparinized blood was allowed to sediment at $37^{\circ} \mathrm{C}$ in a $5 \% \mathrm{CO}_{2}$ atmosphere, and the resulting buffy coat was washed once and suspended in the appropriate media. For all other experiments, neutrophils were purified by the Ficoll-Hypaque centrifugation technique (13). Heparinized $(5 \mathrm{U} / \mathrm{ml})$ venous blood was allowed to sediment after addition of dextran (Gentran 75, Travenol Laboratories, Inc., Morton Grove, Ill.). The supernate was centrifuged at $450 \mathrm{~g}$ for $5 \mathrm{~min}$, and the cell button resuspended in $1 \mathrm{~cm}^{3}$ of Hanks' balanced salt solution containing $0.5 \%$ human serum albumin. Contaminating erythrocytes were lysed by addition of distilled deionized 
water for $20 \mathrm{~s}$ followed by reconstitution to isotonicity with $3.6 \%$ sodium chloride. The leukocytes were resuspended in a small volume of Hanks' balanced salt solution containing $0.5 \%$ human serum albumin and then layered onto a FicollHypaque (Pharmacia Fine Chemicals, Piscataway, N. J.) gradient, centrifuged at $400 \mathrm{~g}$ at $40^{\circ} \mathrm{C}$ for $30 \mathrm{~min}$, washed twice, and finally resuspended to appropriate concentration in Hanks' balanced salt solution containing $0.5 \%$ human serum albumin or the appropriate media. The resulting preparations were $95-99 \%$ neutrophils and free of erythrocytes and their ghosts.

Lysozyme. Human lysozyme was isolated from the urine of patients with monocytic and myelomonocytic leukemia with a bentonite absorption technique (14). By sodium dodecyl sulfate gel chromatography (Fig. 1) the purified lysozyme showed a major component in the molecular weight range of 15,000-daltons and a trace unidentified component in the 30,000 -dalton range. It is possible that this contaminant is a dimer of lysozyme, but this has not been determined. Purified hen eggwhite lysozyme was obtained from Sigma Chemical Co., St. Louis, Mo.

Inhibitors of lysozyme. Antiserum to human lysozyme was prepared in rabbits as described (14). This antiserum produced a single precipitin line by immunodiffusion with human lysozyme but did not react with eggwhite lysozyme. The trisaccharide of $N$-acetylglucosamine (tri-NAG) was generously supplied by Dr. Gustave E. Leinhard. tri-NAG irreversibly inhibits the enzymatic activity of both human and eggwhite lysozyme by blockage of the active site (7).

Chemotaxis studies. The agarose chemotaxis assay was slightly modified from that described by Nelson et al. (15); i.e., agarose (Litex, Denmark) was used in place of indubiose. Each agarose chemotaxis plate consisted of six triplets of wells cut with a template in radial fashion. A pooled sample of heat-inactivated human serum was placed in the inner wells to assess random migration of buffy coat cells. These cells, suspended in 10 times minimal essential media with Earl's balanced salt solution and adjusted to $\mathrm{pH} 7.4$, were placed in the center wells at a concentration of $2.5 \times 10^{7} / \mathrm{ml}$. The different chemotaxins (described below) were placed in outer wells and the plates incubated at $37^{\circ} \mathrm{C}$ in a $5 \% \mathrm{CO}_{2}$ atmosphere for $3 \mathrm{~h}$. The distance from the outer edge of the center wells to the leading border of migrating cells was measured with a microprojector. We confirmed the observation of Nelson et al. (15) that neutrophils make up the majority of migrating cells during the 3 - $h$ period of observation. In

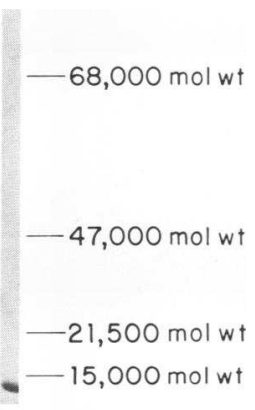

\section{SDS-PAGE}

FIGURE 1 Sodium dodecyl sulfate gel electrophoresis of purified human lysozyme obtained from urine of patients with monocytic leukemia. There is one major band with $\cong 14,500$ mol wt, and a very faint band with $\cong 30,000 \mathrm{~mol} \mathrm{wt}$. some experiments Ficoll-Hypaque purified neutrophils, rather that whole buffy coat preparations, were used. The chemotaxins used were zymosan-activated serum, culture filtrates of Escherichia coli, and the synthetic dipeptide $N$-formylmethionylphenylalanine. The zymosan-activated serum and $E$. coli filtrates were prepared as described $(16,17)$; the synthetic dipeptide, generously supplied by Dr. Robert Nelson, was used at a concentration of $0.1 \mu \mathrm{M}$, a level previously shown to promote maximal chemotaxis in the agarose system.

The effects of lysozyme on neutrophil chemotaxis was tested by preincubating the cells with various concentrations of human, or eggwhite, lysozyme, or with media alone, for $30 \mathrm{~min}$ in a shaking $37^{\circ} \mathrm{C}$ water bath before assay. In other experiments, lysozyme was added directly to zymosanactivated serum (not to cells), incubated for $30 \mathrm{~min}$ at $37^{\circ} \mathrm{C}$, and used as the chemotaxin in the outer well of the agarose system. When appropriate, we incubated the lysozyme inhibitor, tri-NAG, with lysozyme and neutrophils for $30 \mathrm{~min}$ at $37^{\circ} \mathrm{C}$ before placing the mixtures in the center wells.

Inflammatory skin exudates. Rebuck (18) skin windows were constructed on the shaved backs of anesthetized male guinea pigs by abrading $2 \mathrm{~cm}$ contiguous areas of skin with a sterile scalpel. $0.1 \mathrm{ml}$ of human or egg white lysozyme $(500 \mu \mathrm{g} / \mathrm{ml})$ was placed on one area, and media on the other. Glass coverslips were secured and removed at 30 -min intervals for 5-h, with replacement of lysozyme or media at each change.

Oxygen metabolism of PMN. Oxidation of glucose by PMN via the hexose monophosphate shunt was assayed with $1-{ }^{14} \mathrm{C}$-labeled glucose as described (19). Purified neutrophils were suspended at a concentration of $4 \times 10^{6} / \mathrm{ml}$ in medium 199 and incubated in $25 \mathrm{ml}$ Erlenmeyer flasks with $100 \mu \mathrm{Ci}$ of $1-{ }^{14} \mathrm{C}$-labeled glucose (New England Nuclear, Boston, Mass.) either with or without methylene blue added to give maximum hexose monophosphate shunt stimulation. When appropriate, human or eggwhite lysozyme was added to final concentration of $500 \mu \mathrm{g} / \mathrm{ml}$. After incubation for $2 \mathrm{~h}$ at $37^{\circ} \mathrm{C}$ in a shaking water bath, perchloric acid was added; evolved ${ }^{14} \mathrm{C}$-labeled $\mathrm{CO}_{2}$ was trapped in $0.3-\mathrm{ml}$ of Hyamine (Rohm and Hass, Philadelphia, Pa.) in plastic center wells suspended over the cell suspension and counted after solubilization in $10 \mathrm{ml}$ of scintillation fluid in a Beckman scintillation counter (Beckman Instruments, Inc., Spinco Div., Palo Alto., Calif.).

Superoxide anion was measured by cytochrome $c$ assay as described by Goldstein et al. (20). The specificity of cytochrome $c$ reduction assay was determined by treating the reaction mixtures with $10 \mu \mathrm{g} / \mathrm{ml}$ of superoxide dismutase; the superoxide dismutase-inhibited superoxide generation was expressed as nanomoles of cytochrome $c$ reduced per $10^{6} \mathrm{PMN}$.

Ancillary studies. PMN phagocytosis was assayed by a modification of the cophagocytosis methods of Chang (21), and Cannarozzi and Malawista (22) using serum-opsonized zymosan particles suspended in media containing ${ }^{125}$ I-serum albumin. In this technique, the ${ }^{125}$ I-labeled albumin is incorporated into the cells when they phagocytose the opsonized particles, and intracellular radioactivity of washed PMN serves as a measure of phagocytic activity. Cyclic AMP was measured as described by Hatch et al. (23). Cell viability was monitored by trypan blue dye exclusion and lactate dehydrogenase release $(24)$.

\section{RESULTS}

Effects of lysozyme on PMN chemotaxis. Chemotactic motility of human PMN was greatly suppressed 


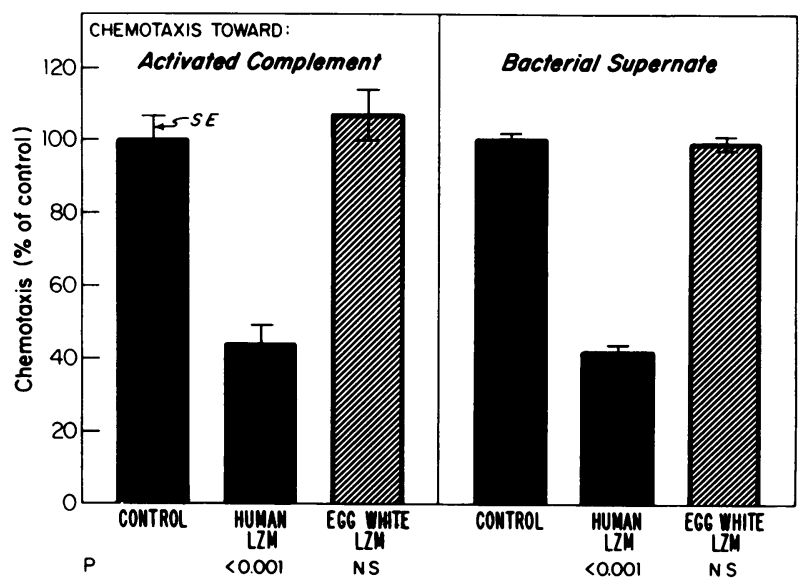

FIGURE 2 Chemotaxis of normal human PMN is inhibited by human, but not eggwhite, lysozyme. Compared to control PMN suspended in media alone, PMN exposed to human lysozyme $(400 \mu \mathrm{g} / \mathrm{ml})$, but not to an identical concentration of eggwhite lysozyme, manifest significantly diminished chemotaxis toward activated complement (left) and E. coli culture supernate (right). Eggwhite lysozyme remained ineffective even at 10-fold increased concentration (not shown). Because PMN migration varied from day-to-day, results are expressed in relation to the migration of untreated control cells run in parallel and depicted as $100 \%$.

by human, but not eggwhite, lysozyme (Fig. 2). Significant inhibition was noted over the concentration range, $10-1,000 \mu \mathrm{g} / \mathrm{ml}$, and was evident when either activated complement (Fig. 2, left), E. coli culture filtrates (Fig. 2, right), or $\mathrm{N}$-formylmethionylphenylalanine (not shown) were used as chemotaxins. The lowest effective concentration, $10 \mu \mathrm{g} / \mathrm{ml}$, inhibited chemotaxis toward activated complement by $30 \% ; 1 \mu \mathrm{g} / \mathrm{ml}$ was without effect. In contrast, lysozyme caused no significant change in random PMN movement (not shown). This inhibitory effect of human lysozyme on PMN chemotaxis was still demonstrated after four washings of the preincubated neutrophils. Inhibition of chemotaxis by lysozyme was noted with purified PMN and buffy coat preparations, excluding the possibility that lysozyme causes the release of a migration inhibition factor from mononuclear cells. Further evidence that lysozyme acts directly on cells rather than as a chemotaxin inactivator was obtained by mixing lysozyme with the chemotaxins and demonstrating no inhibition of cell movement. Furthermore, lysozyme per se did not act as a chemotaxin even when added to the outer wells at very high concentrations $(10,000 \mu \mathrm{g} / \mathrm{ml})$ (Table I).

Effects of lysozyme on cell migration in vivo. When applied directly to Rebuck skin windows, human lysozyme markedly inhibited the movement of PMN into the skin inflammatory exudates (Fig. 3). In separate experiments (not shown) we found eggwhite lysozyme had no effect on the skin inflammatory response and also confirmed that neither lysozyme preparation altered
TABLE I

Lack of Effect of Human Lysozyme (HLZM) when Added to Agarose Chemotaxin Wells

\begin{tabular}{llr}
\hline \multicolumn{1}{c}{$\begin{array}{c}\text { Material added to } \\
\text { chemotaxin well }\end{array}$} & \multicolumn{1}{c}{$\begin{array}{c}\text { Directed } \\
\text { migration }\end{array}$} & $\begin{array}{c}\text { Random } \\
\text { migration }\end{array}$ \\
\hline & \multicolumn{2}{c}{$c m$} \\
Zymosan-activated serum & $9.19 \pm 0.26(\mathrm{SE})$ & $1.83 \pm 0.11$ \\
$+\mathrm{HLZM}, 500 \mu \mathrm{gm} / \mathrm{ml} *$ & $9.28 \pm 0.28$ & $1.84 \pm 0.13$ \\
$\mathrm{HLZM}, 500 \mu \mathrm{gm} / \mathrm{ml}$ & $0.82 \pm 0.08$ & $0.92 \pm 0.10$ \\
$\mathrm{HLZM}, 1,000 \mu \mathrm{gm} / \mathrm{ml}$ & $1.0 \pm 0.15$ & $1.0 \pm 0.12$ \\
$\mathrm{HLZM}, 10 \mathrm{mg} / \mathrm{ml}$ & $1.3 \pm 0.2$ & $1.63 \pm 0.34$ \\
\hline
\end{tabular}

* HLZM was added to zymosan activated sera and incubated at $37^{\circ} \mathrm{C}$ for $30 \mathrm{~min}$ before addition to chemotaxin well.

the ability of PMN to adhere to the glass coverslips used in these studies.

Effects of lysozyme on oxidative metabolism of $P M N$. Human lysozyme significantly inhibited the burst of hexose monophosphate shunt metabolism caused by incubating PMN with methylene blue (Fig. 4, left) but did not suppress resting metabolic activity (not shown). Human lysozyme also inhibited the production of superoxide anion by PMN stimulated by opsonized zymosan particles (Fig. 4, right) and phorbol myristate acetate, (Table II). However, once triggered by either stimulus, superoxide anion production could not be shut off, even when human lysozyme was added within $1 \mathrm{~min}$ of the triggering stimulant (Table II). That inhibition of superoxide anion production by phagocytosing PMN did not result from a suppression of phagocytosis by human lysozyme was validated by electron microscopic examination of granulocytes during their phagocytosis of opsonized zymosan particles. In ancillary cophagocytosis studies, which permits semiquantitation of phagocytosis $(21,22)$, human lysozyme actually slightly potentiated (by $10-20 \% ; P<0.01$ ) the phagocytic capacity of PMN toward opsonized zymosan particles.

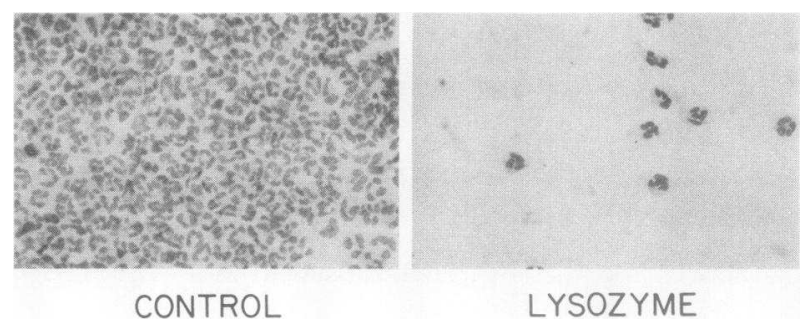

FIGURE 3 Rebuck skin windows on the back of a male guinea pig. Compared to the migration of PMN to a glass coverslip placed on an untreated abraded area (left), a marked paucity of cells is noted in a neighboring area to which human lysozyme $(500 \mu \mathrm{g} / \mathrm{ml})$ had been added (right). Representative fields $3 \mathrm{~h}$ after abrasion are shown. Similar results were obtained in four other guinea pigs. 
TABLE II

Effects of Human Lysozyme (HLZM) on Superoxide $\left(\mathrm{O}_{2}^{-}\right)$

Generation by PMN Stimulated by Serum-Opsonized

Zymosan Particles (STZ) or by Phorbolmyristate Acetate*

\begin{tabular}{lcc}
\hline \multirow{2}{*}{ Addition } & $\mathrm{O}_{2}^{-}$ & $\mathrm{O}_{2}^{-}$ \\
$(\mathrm{STZ})$ & $(\mathrm{PMA})$ \\
\hline
\end{tabular}

None

HLZM before stimulant

$18.2 \pm 0.22(\mathrm{SE})$

$31.0 \pm 0.15$

$8.0 \pm 0.10$

$20.0 \pm 0.45$

HLZM after stimulant

$18.0 \pm 0.10$

$28.8 \pm 0.40$

* HLZM $(500 \mu \mathrm{g} / \mathrm{ml})$ was added to PMN 1 min before or after the oxygen metabolism stimulant.

Reversal of human lysozyme effects on PMN by specific inhibitors. Lysozyme interacts specifically with $\beta 1-4$ glycosidic linkages on bacterial cell walls (25), and oligosaccharide derivatives of these cell walls can bind irreversibly to lysozyme and prevent, thereby, its lytic effects on Micrococcus luteus (26). One such oligosaccharide, a trisaccharide of $\mathrm{N}$-acetylglucosamine, acts as a specific substrate inhibitor of lysozyme (26) and strikingly suppressed the observed effects of human lysozyme on PMN function. The inhibition of PMN chemotaxis by human lysozyme was reversed (albeit not completely) if tri-NAG was added at a concentration of $0.5 \mathrm{mM}$ before the human lysozyme $(500 \mu \mathrm{g} / \mathrm{ml})$ (Table III); tri-NAG alone had no effect on PMN movement (not shown). The inhibition by human lysozyme of triggered PMN superoxide generation was also blocked by tri-NAG (Table III). Rabbit antibody to human lysozyme also reversed the inhibition of superoxide anion generation by lysozyme treated PMN (Table III). Neither tri-NAG nor antilysozyme affected superoxide anion generation when added alone (not shown).

Effects of human lysozyme on PMN cyclic AMP levels.

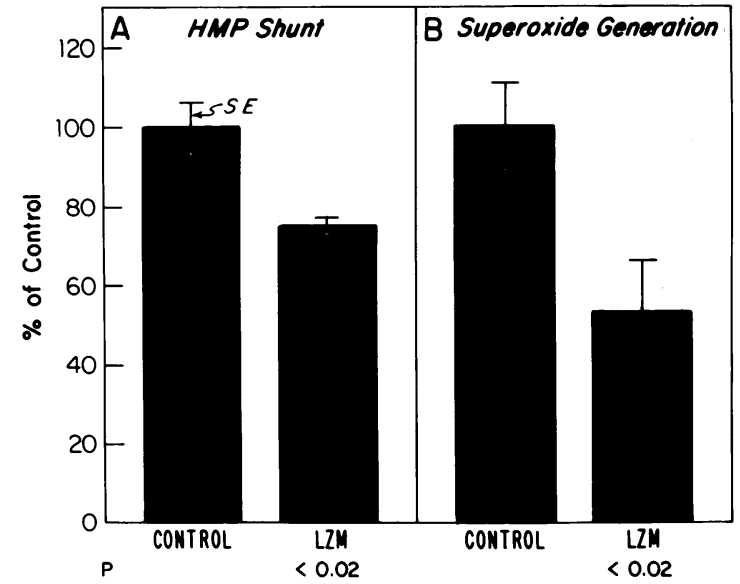

FIGURE 4 Human lysozyme inhibits oxidative metabolism (left) and superoxide generation (right) of stimulated normal human PMN. Lysozyme $(500 \mu \mathrm{g} / \mathrm{ml})$ significantly depressed: (a) HMP shunt activity of methylene blue $(1 \mathrm{mM})$-treated $\mathrm{PMN}$; and $(b)$ superoxide generation by PMN ingesting opsonized zymosan particles. Because PMN metabolism varied from day-to-day, results are expressed in relation to activities in control cells suspended in buffer alone and run in parallel.

Other suppressors of PMN chemotaxis have been shown to cause stimulation of intracellular cyclic AMP (23). Human lysozyme at concentrations up to $500 \mu \mathrm{g} / \mathrm{ml}$ did not affect the basal or stimulated (by prostaglandin $\mathrm{E}_{1}$ or isoproterenol) cyclic AMP levels of PMN (Table IV).

Cell viability. No loss of cell viability occurred when PMN were incubated with as much as 1,000 $\mu \mathrm{g} / \mathrm{ml}$ human lysozyme for as long as $3 \mathrm{~h}$ as documented by both trypan blue dye exclusion and lactate dehydrogenase release assays.

\section{DISCUSSION}

The present studies demonstrate that human lysozyme is capable of modulating the function of human PMN

TABLE III

tri-NAG or Antilysozyme Antibody Reverses Lysozyme Effects on PMN*

\begin{tabular}{|c|c|c|c|c|c|}
\hline Addition & & $\begin{array}{l}\text { Chemotactic } \\
\text { migration }\end{array}$ & $P$ & $\begin{array}{c}\mathrm{O}_{\mathbf{2}}^{-} \\
\text {Generation }\end{array}$ & $P$ \\
\hline & & $\mathrm{cm}$ & & nmol/10 $10^{6}$ PMN & \\
\hline None & & $10.23 \pm 0.35(\mathrm{SE})$ & - & $17.18 \pm 1.99$ & - \\
\hline Lysozyme & & $6.14 \pm 0.31$ & $<0.001$ & $9.27 \pm 1.28$ & $<0.02$ \\
\hline Lysozyme & $P<0.001$ & & & & \\
\hline+ tri-NAG & & $8.60 \pm 0.28$ & $<0.005$ & $18.20 \pm 1.10$ & NS \\
\hline + anti-lysozyme & & - & - & $16.20 \pm 2.00$ & NS \\
\hline
\end{tabular}

* $0.5 \mathrm{mM}$ of tri-NAG was added to PMN $30 \mathrm{~min}$ before lysozyme $(500 \mu \mathrm{g} / \mathrm{ml})$; control cells were preincubated in media alone. Superoxide generation was measured in PMN stimulated with opsonized zymosan particles; rabbit antilysozyme antibody at equivalence was added to lysozyme before its exhibition to PMN. 
TABLE IV

Lack of Human Lysozyme (HLZM) Effect on Cyclic AMP Levels of Resting or Stimulated PMN*

\begin{tabular}{cllc}
\hline Additive & $\begin{array}{c}\text { Cyclic AMP } \\
\text { stimulant }\end{array}$ & \multicolumn{1}{c}{ Cyclic AMP } & $\begin{array}{c}\text { Fold } \\
\text { stimulation }\end{array}$ \\
\hline \multirow{3}{*}{ Media alone } & & pmollmg protein & \\
& None & $1.53 \pm 0.18(\mathrm{SE})$ & - \\
& Isoproterenol & $4.55 \pm 0.33$ & 3.0 \\
& PGE $_{1}$ & $8.55 \pm 0.43$ & 5.6 \\
Plus HLZM & None & $1.40 \pm 0.10$ & - \\
$(100 \mu \mathrm{g} / \mathrm{ml})$ & Isoproterenol & $4.35 \pm 0.05$ & 3.1 \\
& PGE $_{1}$ & $8.35 \pm 0.15$ & 6.0 \\
Plus HLZM & None $_{(500 \mu \mathrm{g} / \mathrm{ml})}$ & $1.95 \pm 0.05$ & - \\
& Isoproterenol & $5.85 \pm 0.45$ & 3.0 \\
& PGE $_{1}$ & $12.50 \pm 1.00$ & 6.4 \\
\hline
\end{tabular}

* Media alone, isoproterenol $(1 \mu \mathrm{M})$, or prostaglandin (PGE), $(0.1 \mu \mathrm{M})$ was added to purified PMN at $37^{\circ} \mathrm{C}$ for $2 \mathrm{~min}$ before TCA precipitation and cyclic AMP assay.

in vitro. This modulation, manifested by reduction in PMN movement towards three different chemotaxins as well as by inhibition of triggered oxidative metabolism, takes place without changes in cell viability or intracellular cyclic AMP levels. These effects were demonstrated by physiologically relevant concentrations of human lysozyme but not by hen eggwhite lysozyme that has a comparable molecular weight and charge. As noted, the human lysozyme preparation used in these studies contained a trace amount of an unidentified contaminant with a molecular weight in the range of 30,000 daltons. Whereas the possibility that this constituent, rather than lysozyme per se, was responsible for the demonstrated effects on PMN cannot be categorically excluded, the blockage of these functions by tri-NAG and antilysozyme strongly supports the role of lysozyme.

The concept that a protein secreted continuously by cells of the monocyte macrophage complex (1) and present in high concentrations in inflammatory exudates (27) may serve as a regulator of inflammatory events is an intriguing one. By inhibiting cell movement, lysozyme may serve to both limit further PMN accumulation and to trap cells already present at the inflammatory site - effects that might serve to decrease tissue injury attendant to inflammation. This suggested protective effect of lysozyme would be potentiated by its concomitant ability to suppress formation of toxic oxygen radicals whose accumulation would also be damaging to tissues. Because these activities, which in concert appear to quiet the inflammatory response, are promulgated at concentrations of lysozyme extant in inflammatory exudates $-\cong 10-125 \mu \mathrm{g} / \mathrm{ml}(27,28)-$ and occur without concomitant compromise of the phagocytic capacity of PMN, it appears that lysozyme can suppress what might otherwise be excessive tissue damage without critically restricting host defense.

The mechanism by which lysozyme quiets PMN is unclear, but we postulate that the plasma membrane is the site of its action. That lysozyme can affect mammalian membranes in other systems has been documented by observations that it alters the surface morphology of transformed human hepatocytes in culture (11), and that it agglutinates rat mitochondria by interacting with their membranes at sites which also bind concanavalin A (29). In the present studies we have shown that extensive washing of PMN after their exposure to lysozyme does not reverse its inhibition of chemotaxis. We have also found that the oligosaccharide, tri-NAG, reverses the inhibition. These findings suggest that human lysozyme binds to a polysaccharide moiety in the PMN membrane. Our finding that eggwhite lysozyme did not alter cell movement suggests that the human lysozyme effect is not simply a result of its marked cationic charge.

Neutrophil locomotion involves complex and sequential biochemical events mainly involving the cell membrane and its submembraneous filamentous structures (30). Several types of chemotaxis inhibitors - many affecting the PMN membrane - have been described; one of these is derived from leukocytes, per se (31). This observation, along with the present evidence that lysozyme inhibits PMN chemotaxis, suggests that negative feedback mechanisms may regulate inflammatory responses. Similar inflammatory modulation may derive from the capacity of immune complexes to inhibit PMN motility (32), as well as from the fact that during the lysosomal enzyme release reaction, PMN chemotaxis is also transiently inhibited (33). Another type of chemotaxis inhibition results from exposure of PMN to one chemotaxin that competes with another chemotaxin for membrane binding sites; such inhibition is generally reversible (34-37). Some chemotaxins, when incubated with PMN at high concentrations cause irreversible inhibition of chemotactic response to subsequent challenge - a process known as deactivation (38). Because lysozyme was itself not found to be chemotactic (Table I), its mechanism of inhibition is evidently not that of deactivation. In addition, chemotactic factor inactivators in normal serum have been described $(39,40)$ that inactivate complement-derived chemotactic fragments. It appears that human lysozyme is also distinct from these inactivators in that its addition to complement-activated serum causes no alteration in chemotaxis (Table I). Finally, cyclic nucleotides evidently play an important role in PMN locomotion $(41,42)$. Inhibitors of chemotaxis generally have been found to increase intracellular cyclic AMP levels (23). Thus, we find it somewhat surprising that neither human or eggwhite 
lysozyme affect basal or stimulated PMN cyclic AMP levels. The exact mechanism by which human lysozyme inhibits PMN chemotaxis remains for further study.

Production of activated oxygen compounds (20), another membrane-dependent function of PMN, was also found to be inhibited by human, but not eggwhite, lysozyme. However, when lysozyme was added as briefly as 1 min after any of several diverse stimulants of free radical production (e.g., opsonized zymosan particles, phorbol myristate acetate, or methylene blue) its inhibiting effect was lost (Table II). It therefore appears that lysozyme inhibits superoxide generation directly and does not quench already formed superoxide anion. As with chemotaxis inhibition, the fact that the tri-NAG prevents lysozyme suppression of triggered toxic oxygen radical production suggest that PMN membranes (and particularly their saccharide constituents) are the site of this lysozyme modulating activity as well.

Although the bacteriolytic activity of lysozyme has suggested that this enzyme is primarily involved in host bacterial defenses, we postulate that a different, and perhaps more important physiologic role is manifest by the enzyme - that of inflammation modulator. In this regard, we consider it likely that lysozyme is not the only modulating factor. Other substances at sites of inflammation, such as C5 fragments, platelets, oxidized lipids and so on, may have important effects as well. Conversely, it remains to be determined whether this proposed beneficial activity of lysozyme may become deleterious in patients with hyperlysozymemia, i.e., with sarcoidosis or monocytic leukemia $(14,43)$. This possibility is suggested by the findings of Maderazo et al. (43) that PMN chemotaxis is suppressed in sarcoidosis, and by our own preliminary studies (12) that this chemotactic defect is corrected by adding triNAG to sarcoidosis plasma.

\section{REFERENCES}

1. Gordon, S., A. Todd, and Z. A. Cohn. 1974. In vitro synthesis and secretion of lysozyme by mononuclear phagocytes. J. Exp. Med. 139: 1228-1248.

2. Cohn, Z. A. 1968. The differentiation of macrophages. In Symposium of the International Society of Cell Biology. K. B. Warren, editor. 7: 101.

3. Fleming, A. 1922. On a remarkable bacteriolytic element found in tissues and secretions. Proc. R. Soc. Lond. B. Biol. Sci. 93: 306-317.

4. Amano, T., S. Inai, Y. Seki, S. Kashiba, K. Fujikawa, and S. Nishimura. 1954. Studies on the immune bacterial lysis. I. Accelerating effects on the immune bacteriolysis by lysozyme like substance of leukocytes and eggwhite lysozyme. Med. J. Osaka Univ. 4: 401-418.

5. Fleming, A., and W. D. Allison. 1927. The development of strains of bacteria resistant to lysozyme action and the relation of lysozyme action to intracellular digestion. $\mathrm{Br}$. J. Exp. Pathol. 8: 214-218.

6. Thompson, R. 1940. Lysozyme and its relation to the anti- bacterial properties of various tissues and secretions. Arch. Pathol. 30: 1096-1131.

7. Chipman, D. M., and N. Sharon. 1969. Mechanism of lysozyme action. Science (Wash. D. C.). 165: 454-465.

8. Sultan, M. R. 1971. The bacterial membrane. In Biomembranes. L. A. Manson, editor. Plenum Publishing Corp., New York. 1: 1-65.

9. Glen, A. A. 1968. Lysozyme: antigen, enzyme, and antibacterial agent. In The Scientific Basis of Medicine, Annual Reviews, London, University of London, Alathlone Press. 32-52.

10. Glick, A. D., A. M. Ranhand, and R. M. Cole. 1972. Degradation of group A streptococcal cell walls by eggwhite lysozyme and human lysosomal enzymes. Infect. and Immun. 6: 403-413.

11. Osserman, E. F., M. Klockars, J. Halper, and R. E. Fischel. 1973. Effects of lysozyme on normal and transformed mammalian cells. Nature (Lond.). 243: 331-335.

12. Gordon, L. I., S. D. Douglas, N. E. Kay, O. Yamada, E. Osserman, and H. S. Jacob. 1978. Modulation of inflammation by lysozyme, a product of inflammatory cells. Clin. Res. 26: 554A. (Abstr.)

13. Cutts, J. H. 1970. Cell separation: methods in hematology. Academic Press, Inc., New York. 49-54.

14. Osserman, E. F., and D. P. Lawlor. 1966. Serum and urinary lysozyme (muramidase) in monocytic and myelomonocytic leukemia. J. Exp. Med. 124: 921-951.

15. Nelson, R. D., P. G. Quie, and R. L. Simmons. 1975. Chemotaxis under agarose: a new and simple method for measuring chemotaxis and spontaneous migration of human polymorphonuclear leukocytes and monocytes. $J$. Immunol. 115: 1650-1656.

16. Ward, P. A. 1968. Chemotaxis of mononuclear cells. J. Exp. Med. 128: 1201-1221.

17. Ward, P. A., I. H. Lepow, and L. H. Newman. 1968. Bacterial factors chemotactic for polymorphonuclear leucocytes. Am. J. Pathol. 52: 725-736.

18. Rebuck, J. W., and J. H. Crowley. 1955. A method of studying leukotactic function in vivo. Ann. N. Y. Acad. Sci. 59: 757-805.

19. Keusch, G. T., S. D. Douglas, D. Mildvan, and S. Hirschman. $1972 .{ }^{14} \mathrm{C}$-glucose oxidation in whole blood: a clinical assay for phagocyte dysfunction. Infect. Immun. 5: 414-415.

20. Goldstein, I. M., D. Roos, H. B. Kaplan, and G. Weissman. 1975. Complement and immunoglobulins stimulate superoxide production by human leukocytes independently of phagocytosis. J. Clin. Invest. 56: 1155-1163.

21. Chang, Y. 1969. Studies on phagocytosis. Exp. Cell Res. 54: 42-48.

22. Cannarozzi, N. A., and S. E. Malawista. 1973. Phagocytosis by human blood leukocytes measured by the uptake of $I^{131}$ labeled human serum albumin: inhibitory and stimulating effects of cytochalasin B. Yale J. Biol. Med. 46: $177-189$.

23. Hatch, G. E., W. K. Nichols, and H. R. Hill. 1977. Cyclic nucleotide changes in human neutrophils induced by chemoattractants and chemotactic modulators. J. Immunol. 119: 450-456.

24. Bergmeyer, H. U., editor. 1963. In Methods in Enzymatic Analysis. Academic Press, Inc., New York. 737-739.

25. Jeanloz, R. W., N. Sharon, and H. M. Flowers. 1963. The chemical structure of a disaccharide isolated from micrococcus lysodeikticus cell wall. Biochem. Biophys. Res. Commun. 13: 20-25.

26. Secemski, I. I., S. S. Lehrer, and G. E. Lienhard. 1972. A transition state analog for lysozyme. J. Biol. Chem. 247: $4740-4748$. 
27. Senn, H. J., B. Chu, J. O'Malley, and J. F. Holland. 1970. Experimental and clinical studies on muramidase (lysozyme). I. Muramidase activity of normal human blood cells and inflammatory exudates. Acta. Haematol. (Basel). 44: 65-77.

28. Jenn, R. S., J. G. Tew, and D. M. Donaldson. 1967. Extracellular B-lysin and muramidase in body fluids and inflammatory exudates. Proc. Soc. Exp. Biol. Med. 124: 545-548.

29. Adinolfi, M., J. N. Loeb, and E. F. Osserman. Agglutination of rat liver mitochondria by lysozyme. In Lysozyme. E. F. Osserman, R. E. Oanfield and S. Beychok, editors. Academic Press, Inc., New York. 463-470.

30. Zigmond, S. H. 1978. Chemotaxis by polymorphonuclear leukocytes. J. Cell Biol. 77: 269-287.

31. Goetzl, E. J., and K. F. Austen. 1972. A neutrophil immobilizing factor derived from human leukocytes. J. Exp. Med. 136: 1565-1580.

32. Bumol, T. F., N. E. Kay, and S. D. Douglas. 1978. Effect of phagocytosis and $\mathrm{Fc}$ receptor occupancy on complement dependent neutrophil chemotaxis. J. Lab. Clin. Med. 91: 850-856.

33. Gallin, J. I., D. G. Wright, E. Schiffman, and D. W. Alling. 1978. Inhibition of human neutrophil chemotaxis following exocytosis of lysosomal granule contents. Clin. Res. 26: 395A. (Abstr.)

34. Henson, P. M. 1976. Membrane receptors on neutrophils. Immunol. Commun. 5: 757-774.

35. Schiffman, E., B. A. Cocheran, and S. M. Wohl. 1975. $\mathrm{N}$-formylmethionyl peptides chemoattractants for leukocytes. Proc. Natl. Acad. Sci. U. S. A. 72: 1059-1062.
36. Showell, H. J., R. J. Freer, S. H. Zigmond, E. Schiffman, A. Srivinivesaldratt, B. Corcheran, and E. L. Becker. 1976. The structure activity relations of synthetic peptides as chemotactic factors and inducers of lysosomal enzyme secretion for neutrophils. J. Exp. Med. 143: 1154-1169.

37. Williams, L. I., R. Snyderman, M. C. Pike, and R. J. Lefkowitz. 1977. Specific receptor sites for chemotactic peptides on human polymorphonuclear leukocytes. Proc. Natl. Acad. Sci. U. S. A. 74: 1204-1208.

38. Ward, P. A., and E. L. Becker. 1968. The deactivation of rabbit neutrophils by chemotactic factor and the nature of the activatable esterase. J. Exp. Med. 127: 693-710.

39. Berenberg, J. L., and P. A. Ward. 1973. Chemotactic factor inactivator in normal human serum. J. Clin. Invest. 52: 1200-1206.

40. Brozna, J. P., R. M. Senior, D. L. Kreutzer, and P. A. Ward. 1977. Chemotactic factor inactivator of human granulocytes. J. Clin. Invest. 60: 1280-1288.

41. Estensen, R. D., H. R. Hill, P. G. Quie, N. Hogan, and N. D. Goldberg. 1973. Cyclic GMP and cell movement. Nature (Lond.). 245: 458-460.

42. Hill, H. R., R. D. Estensen, P. G. Quie, N. A. Hogan, and N. D. Goldberg. 1976. Modulation of human neutrophil chemotactic responses by cyclic $3^{\prime}, 5^{\prime}$, guanosine monophosphate and cyclic $3^{\prime}, 5^{\prime}$ adenosine monophosphate. Metab. Clin. Exp. 24: 447-456.

43. Maderazo, E. G., P. A. Ward, C. L. Woronick, J. Kubik, and A. C. DeGraff. 1976. Leukotactic dysfunction in sarcoidosis. Ann. Intern. Med. 84: 414-419. 